\title{
The Valuation and Analysis of Apple Inc.
}

\author{
Bowen Chen ${ }^{1, a}$, Wei Lu ${ }^{2, b}$, and Simeng Wang ${ }^{3, c}$ \\ 1. Beijing No.4 High School International Campus, 100033, China \\ 2. Syracuse University, 13244, United States \\ 3. Hong Kong Baptist University, 999077, China \\ a josephchenbowen67@gmail.com, bwlu115@syr.edu, cwsm990328@163.com
}

\begin{abstract}
In order to define a reasonable value of Apple's stocks, a number of valuation models can be considered, including FCFF model, DDM, VC method, FCFE model and multiples valuation model. In the research, we use WACC and DCF calculation to evaluate the Apple company's further value, and judging whether it is undervalued or overvalued based on historical data and market direction. As different models and data provide various results, they have different limitations and uses. For DCF, although some of the data used in its calculations are based on people's subjective analysis of the future, its valuation serves as a baseline for the target price, making its results relatively conservative and reasonable. Based on the results generated by valuation models, we think Apple still has a great potential to develop, and we advise customers to buy or hold the stock.
\end{abstract}

Keywords: Apple Inc; Valuation; WACC; DCF; Price.

\section{Introduction}

Our goal is to analyze and evaluate Apple Inc. by using its data and WACC and DCFvaluation methods. The result will compare to the current value and decide whether it is overvalued.

Apple Inc. is a multinational technology company that is headquartered in California. It is mainly designed to sell consumer electronics and computer software. Now Apple Inc. is one of the five biggest technology companies. iPhone are widely used by many other countries. Apple's iOS has a 60 percent share of the mobile operating system market in the United States, the highest sharefor both the iPhone and iOS operating systems [1]. Since our group members all use Apple products and people around us mostly use iPhones or iPads, we become interested in the Apple company.

Most of the previous research says Apple was overvalued, but we came out with adifferent conclusion. We think Apple is undervalued since the coming 5G and Covid 19 in 2020 brings us a lot of new factors to value the company.

Therefore, the many factors that affect value make valuation more challenging and uncertain, and it made our decision to choose Apple firmer.

\section{Literature Review}

So, what is the DCF model? "DCF models-which view the intrinsic value of common stockas the present value of its expected future cash flows - are a fundamental tool in both investment management and investment research"[2]. It was developed by John Burr Williams and other analysts in 1938, a model that uses stocks to estimate the future value of a company. John Burr Williams was an American economist, in his text The Theory of Investment Value, he articulated the theory of DCF. To perform a DCF analysis, people must make assumptions about a range of things, including the company's future revenue growth and profitability (cash flow), as well as the company's initial investment interest rate, cost of capital, and possible threats to the company's basic value (discount rate). In the DCF model, WACC is an indispensable part. The weighted average cost of capital (WACC) is a method of measuring a company's cost of capital in which each capital group is weighted proportionately. A WACC estimate takes into account all sources of capital, including common stock, preferred stock, shares and any other long-term debt. According to Pablo Fernandez, a professor in the Department of Financial Management and holder of IESE's Corporate Finance 
Chair, "the WACC is neither a cost nor a required return, but a weighted average of a cost and a required return"[3]. WACC is just a rate, it can be misleading to refer to WACC as "the cost of capital" because it is not a cost. Therefore, we need to calculate WACC so that it can be used as the discount rate in a DCF valuation model.

\section{Theoretical Framework}

We believe the WACC and DCF model are more suitable for a company like Apple. The Company designs, manufactures and markets smartphones, personal computers, tablets, wearables and accessories, and sells a variety of related services. As is known to us all, the DCF model uses past cash flows to estimate the future value of a company, it is suitable for companies that have been publicized for years and have stable annual revenue. Because the valuation of the DCF modelis supported by relatively rigorous theory and data, it is carried out from the actual value drivers of enterprises, and it is an important valuation model to discover the value drivers of companies [4].

Besides, we also want to talk about VC methods and the reason why we don't choose them. Even though we learnt about the VC method, the group members and I don't believe that the VC method isa reasonable calculation for a company like apple. Because the VC method is the judgment of capital market participants on the value of a company at a particular stage, it can be very effective to evaluate private companies, especially the startups. Apple, however, is a company that has formed for more than 40 years, and their stock has also been listed for nearly forty years. Clearly, using the VC method to calculate Apple's value is inappropriate and imprecise.

$$
\begin{gathered}
W A C C=[(E \div V) \times R e]+[(D \div V) \times R d] \times(1-T) \\
V=\frac{F C F}{1+r}+\frac{F C F(1+g)}{(1+r)^{2}}+\cdots
\end{gathered}
$$

To calculate Apple's value in 2025, we need to find Apple's WACC first. For WACC calculation, we first found all the data needed to calculate WACC: Backstock price, outstanding shares, debt, market value of the firm's debt, market value of the firm's equity, risk-free rate, beta, market return, Interest expense, market value of debt, income tax expense, and income before tax. Then, we used the formulas to calculate Apple's equity, V, E/V, D/V, Re, Rd, and TC. Then, we used the WACC formula and got the result 7.75\%. Now, we know Apple's WACC in 2020, so we could other datab estimate Apple's revenue and company value over the next five years and determine whether Apple is being undervalued or overvalued.

Table 1 is the graph of Apple WACC calculation, which lists all the data and formulas used to calculate DCF that mentioned above.

For the DCF calculation, we already got R which means WACC and equals $8 \%$. For apple's average growth rate, because in the past five years, apple's overall growth rate showed an upward trend, and in 2020, their growth rate reached $5.51 \%$, so we reasonably predicted that the growth rate in the next five years will be $5.5 \%$. For the revenue growth rate, we predicted it will increase first then decrease and then stay stable. Because in $2021,5 \mathrm{G}$ will be gradually rolled out. At the same time, the United States has suppressed Chinese mobile phones represented by Huawei. So, Apple will have a relatively rapid growth rate from 2021 to 2022. Using the predicted growth rate, we can get the five years revenue. 
Table 1. Apple Wacc calculation

\begin{tabular}{|c|c|c|c|}
\hline Wacc $=\mathbf{D} / \mathbf{V} * \mathbf{R d} *(\mathbf{1 - t})+\mathbf{E} / \mathbf{V} * \mathbf{R e}$ & & & \\
\hline $\mathbf{R e}=\mathbf{R f}+\boldsymbol{\beta e} * \mathbf{M R P}$ & & & \\
\hline $\mathbf{R d}=\mathbf{R f}+\boldsymbol{\beta d} * \mathbf{M R P}$ & & & \\
\hline $\boldsymbol{\beta e}=\boldsymbol{\beta a}+\mathbf{D} / \mathbf{E}(\boldsymbol{\beta a}-\boldsymbol{\beta d})$ & & & \\
\hline Inputs & & & \\
\hline Target Leverage & $\mathbf{4 . 9 0 \%}$ & & \\
\hline Corporate Tax Rate & $14.40 \%$ & & \\
\hline Risk Free Rate 10y & $2.90 \%$ & & \\
\hline Market Risk Premium & $\mathbf{4 \%}$ & & \\
\hline Cost of Debt & & & $\mathbf{D} / \mathbf{V}$ \\
\hline Debt beta & & & $5 \%$ \\
\hline Rd & $\mathbf{0 . 2}$ & $\mathbf{( 1 - t )}$ & \\
\hline Cost of Equity & $2.84 \%$ & $85.60 \%$ & \\
\hline Assets beta & & & \\
\hline Equity beta & & & $\mathbf{E} / \mathbf{V}$ \\
\hline Re & & & $95 \%$ \\
\hline Wacc & 1.25 & & \\
\hline
\end{tabular}

According to the past five years of data, the operating margin is approximately $27 \%$. So, we can get the EBIT for the next five years. After we minus the tax, we got every year's EBIAT. As weall acknowledged, Free Cash Flow is calculated by 'EBIT minus tax, plus depreciation and then minus capital expenditure and change in net working capital'. Since we had apple company's data for 2019 and 2020, we predicted every data's growth rate for the next five years. For the rate of Deprec. \& Amort., because its growth rates in 2019 and 2020 were $5.87 \%$ and $5.01 \%$ respectively, and Apple has a lot of intangible assets, such as patent technology and amortization of research anddevelopment expenses. Thus, we conservatively estimate Apple's Deprec. \& Amort. the growth rate will remain unchanged in the next five years. For the rate of capital expenditures, because in 2019 and 2020, its growth rate was $14.37 \%$ and $13.39 \%$ respectively, and Apple has a lot of outsourcing operations in foreign countries, such as building factories in China, Vietnam and other places, which reduces their fixed asset spending. Therefore, we think that Apple's outsourcing enterprises will increase in the next five years and assume that its rate will decrease by 1\% every year. All the 2019 and 2020 data mentioned above are from Apple's 10-K report and Yahoo's website [5][6]. After we calculated the company's data for the next five years, we followed the formula and got the free cash flow. Next, we used WACC to calculate the present value of FCF. In the end, we got the total value and the equity value, then used equity value to divide share outstanding and got the valued stock price, which equals to $\$ 287.26$. Compare it to the present market price of $\$ 120$, wecan conclude that Apple is undervalued.

Table 2 is the graph of Apple DCF calculation, which lists all the data used to calculate DCF that mentioned above. 
Table 2. Apple DCF calculation

\begin{tabular}{|c|c|c|c|c|c|c|}
\hline Item & 2020 & $2021 F$ & $2022 F$ & $2023 F$ & $2024 F$ & $2025 \mathrm{~F}$ \\
\hline Revenues & $\$ 274,515$ & $\$ 343,143.8$ & $\$ 411,772.500$ & $\$ 473,538.40$ & $\$ 520,892.20$ & $\$ 562,563.60$ \\
\hline Revenue Growth Rate & $5.51 \%$ & $25 \%$ & $20 \%$ & $15 \%$ & $10 \%$ & $8 \%$ \\
\hline Operating Profit(EBIT) & $\$ 69,964$ & $\$ 92,648.83$ & $\$ 111,178.58$ & $\$ 127,855.37$ & $\$ 140,640.89$ & $\$ 151,892.17$ \\
\hline Operating Margin & $25 \%$ & $27.00 \%$ & $27.00 \%$ & $27.00 \%$ & $27.00 \%$ & $27.00 \%$ \\
\hline NWC & $\$ 1,707$ & $\$ 6,945$ & $\$ 1,645$ & $\$ 3,327$ & $\$ 2,386$ & $\$ 3,088$ \\
\hline Year & & 1 & 2 & 3 & 4 & 5 \\
\hline EBIT & 69,964 & $\$ 92,648.83$ & $\$ 111,178.58$ & $\$ 127,855.37$ & $\$ 140,640.89$ & $\$ 151,892.17$ \\
\hline- Tax & $\$ 5,597.12$ & $\$ 13,341.43$ & $\$ 16,009.72$ & $\$ 18,411.17$ & $\$ 20,252.29$ & $\$ 21,872.47$ \\
\hline EBIAT & $\$ 64,366.88$ & $\$ 79,307.40$ & $\$ 95,168.86$ & $\$ 109,444.20$ & $\$ 120,388.60$ & $\$ 130,019.70$ \\
\hline +Deprec.\&Amort. & & $\$ 17,157.20$ & $\$ 20,588.60$ & $\$ 23,676.90$ & $\$ 26,044.60$ & $\$ 28,128.20$ \\
\hline -Capex & & $\$ 4,411.20$ & $\$ 4,117.70$ & $\$ 2,058.90$ & $-\$ 473.50$ & $-\$ 1,875.20$ \\
\hline -Change in NWC & & $\$ 5,238.00$ & $-\$ 5,300.00$ & $\$ 1,682.00$ & $-\$ 941.00$ & $\$ 702.00$ \\
\hline \multicolumn{2}{|c|}{ Free Cash Flow (FCF) } & $\$ 86,815.40$ & $\$ 116,939.76$ & $\$ 129,380.20$ & $\$ 147,847.70$ & $\$ 159,321.10$ \\
\hline PV (FCF) & & $\$ 80,384.63$ & $\$ 100,257.00$ & $\$ 102,706.17$ & $\$ 108,672.47$ & $\$ 108,431.26$ \\
\hline \multicolumn{2}{|c|}{ Terminal Value in 2025} & & & & & $\$ 6,723,350.42$ \\
\hline Sum of PV (FCF) & $\$ 500,451.54$ & & & & & \\
\hline PV Terminal Value & $\$ 4,575,799.32$ & & & & Tax Rate & $14.4 \%$ \\
\hline \multirow[t]{2}{*}{ Total Value } & $\$ 5,076,250.86$ & & & & Growth Rate & $5.5 \%$ \\
\hline & & & & & WACC & $8 \%$ \\
\hline Equity Value & $\$ 4,822,438.32$ & & & & & \\
\hline Share Outstanding & 16,788 & & & & & \\
\hline Equity value/share & $\$ 287.26$ & & & & & \\
\hline Market price & $\$ 120.00$ & & & & & \\
\hline
\end{tabular}

\section{Conclusion}

In conclusion, by the DCF model, we evaluated Apple's value in five years, and came out with the result that it had been undervalued. Even though our number is extremely high, we believe that our calculation is reasonable. The main reason is we believe that the apple still has lots of potential in the future, even if it has already been one of the most influential IT companies in the world. Therefore, we should believe that Apple will remain among the top companies in the future.

\section{References}

[1] Information on: www.apple.com.

[2] John Burr. Williams. The Theory Of Investment Value. Harvard University Press, 1938, p1-613.

[3] Pablo Fernandez, WACC: Definition, microeconomics and errors. IESE Business School, 2011, p.1-27.

[4] Michael C. Jensen. Agency Costs of Free Cash Flow, Corporate Finance, and Takeovers, American Economic Review, Vol. 76, No. 2, pp. 323-329.

[5] Information on: https://investor.apple.com/investor-relations/default.aspx\#tabs_content--2021.

[6] Information on: Yahoo! Finance. https://finance.yahoo.com/. 